\title{
The effects of coronavirus on human nasal ciliated respiratory epithelium
}

\author{
M.A. Chilvers*, M. McKean*, A. Rutman*, B.S. Myint", M. Silverman*, C. O'Callaghan*
}

\begin{abstract}
The effects of coronavirus on human nasal ciliated respiratory epithelium. M.A. Chilvers, M. McKean, A. Rutman, B.S. Myint, M. Silverman, C. O'Callaghan. (C)ERS Journals Ltd 2001.

ABSTRACT: Human coronavirus (HCoV) accounts for $15-30 \%$ of common colds, but only one case report has described the effect of a coronavirus infection, that was asymptomatic, on human respiratory epithelium.

The authors examined the effects of infection with $\mathrm{HCoV}$ on ciliary structure and function in healthy volunteers infected by intranasal inoculation with $\mathrm{HCoV} 229 \mathrm{E}$. A further four volunteers were sham infected with ultraviolet-inactivated virus. Immediately before inoculation (day 0 ) and 3 days later (day 3 ), ciliated epithelium was obtained by brushing the inferior nasal turbinate. Ciliary beat frequency was determined and beat pattern analysed for evidence of dyskinesia $(0=$ normal, $3=$ severely dyskinetic) using digital high-speed video photography. Ciliary ultrastructure was examined by transmission electron microscopy. Symptom diaries were kept for the duration of the study.

All subjects inoculated with $\mathrm{HCoV}$, including the three who did not develop symptoms of an upper respiratory tract infection, had disruption of their respiratory epithelium on day 3. Although there was no difference in the mean ciliary beat frequency between day $0(11.3 \mathrm{~Hz}(95 \%$ confidence interval (CI): 8.6-14.0) and day $3(9.4 \mathrm{~Hz}(95 \% \mathrm{CI}$ 7.2-11.6), there was a significant increase $(\mathbf{p}<0.05)$ in the ciliary dyskinesia score between day $0(0.2(95 \%$ CI $0-0.5))$ and day $3(1.1(95 \%$ CI $0.5-1.7)$. In sham-infected subjects, no differences in epithelial integrity, or ciliary structure and function were found between day 0 and day 3 .

Inoculation of healthy volunteers with human coronavirus caused disruption of the ciliated epithelium and ciliary dyskinesia. This is likely to impair mucociliary clearance. Damage to the respiratory epithelium, due to human coronavirus infection, may occur without overt clinical symptoms.

Eur Respir J 2001; 18: 965-970.
\end{abstract}

\begin{abstract}
*Childrens Asthma Centre, Dept of Child Health, University of Leicester, Leicester Royal Infirmary, and ${ }^{\#}$ Dept of Microbiology and Immunology, University of Leicester, Leicester, UK.

Correspondence: C. O'Callaghan, Childrens Asthma Centre, Dept of Child Health, University of Leicester, Robert Kilpatrick Clinical Sciences Building, Leicester Royal Infirmary, 6694, P.O. Box 65, Leicester LE2 7LX, UK.

Fax: 441162523282
\end{abstract}

Keywords: Cilia

ciliary beat frequency

coronavirus

respiratory epithelium

ultrastructure

viral infection

Received: October 262000

Accepted after revision June 12001

This work was supported by The Cystic Fibrosis Trust, Masons Medical Foundation and The National Asthma Campaign.
The "common cold" is a universally recognized short illness, in which the main symptoms involve the upper respiratory tract and in which nasal symptoms usually predominate. Understanding the interaction between virus and epithelium is an important step in determining the mechanisms by which symptoms are produced. Structural damage to the respiratory epithelium [1-3] and abnormal ciliary function [1, 4, 5] during viral infection may disrupt the mucociliary escalator $[4,6]$, contributing to symptoms of nasal discharge and obstruction. Although some infected volunteers suffer nasal congestion and discharge, an equal number of infected subjects have no definite symptoms. The reasons for this are still unclear [7].

Human coronaviruses $(\mathrm{HCoV})$ are the second most prevalent cause of the common cold. They account for $15-30 \%$ of proven viral infections [8] and may cause exacerbation of lower respiratory diseases such as asthma [9]. Data on the effect of $\mathrm{HCoV}$ infection of the respiratory epithelium are surprisingly sparse. The initial method for identifying $\mathrm{HCoV}$ used in vitro tracheal organ cultures, in which infection was detected with difficulty. Microscopy of light reflected from the epithelial surface was used as an indicator of ciliary activity, with loss of the light reflection taken as the outcome measure for viral infection [10]. Other data include an incidental finding, on electron microscopy, of $\mathrm{HCoV}$ infection in a 2-yr-old female being investigated for ciliary dyskinesia. It is of interest that this infection was asymptomatic with no signs of a common cold at the time of biopsy or afterwards [11].

In the present study, HCoV 229E (American Type Culture Collection, Rockville, MD, USA), one of the two major serotypes of coronavirus accounting for upper respiratory tract infections [12], was used to inoculate healthy volunteers. The aim was to determine the effect of $\mathrm{HCoV}$ infection on the ultrastructure of nasal epithelium and on the beat frequency and beat pattern of nasal cilia.

\section{Methods}

\section{Subjects}

Fifteen adult volunteers (11 males, four females) without nasal or respiratory disease were recruited. Ages ranged from 18-35 (median 22) yrs. None of the 
subjects were taking nasal drugs and none had had a symptomatic upper respiratory tract infection in the preceding 6 weeks. The study received approval from the Leicestershire Ethical Review Committee.

\section{Human coronavirus inoculation}

HCoV 229E (American Type Culture Collection) was cultured according to standards of good laboratory practice in human embryonic lung fibroblasts. An inoculum was prepared as previously described [13] and was tested for safety according to the criteria of GwALTNEY et al. [14]. The inoculum consisted of aliquots of $1 \mathrm{~mL}$ of $\mathrm{HCoV} 229 \mathrm{E}$ suspension (200 50\% tissue culture infective doses (TCID50) per $\mathrm{mL}$ ) which were stored at $-70^{\circ} \mathrm{C}$. Eleven subjects (nine males and two females) were inoculated with active virus as previously described [7]. Briefly, with the volunteer's head extended to $45^{\circ}, 0.5 \mathrm{~mL}$ of virus was instilled into each nostril.

In addition to viral antigens, the inoculum may contain other small proteins released from the infected cultured cells, such as cytokines. These proteins could interfere with the infective process or even generate an inflammatory response. To control for this, four subjects were inoculated with virus inactivated by ultraviolet (UV) light as previously described [15]. Inactivation was confirmed by culture in human embryonic lung fibroblasts with a control flask inoculated with active virus. The cells with active virus developed complete cytopathic effect by 10 days, whereas those with UV-inactivated virus showed no cytopathic effect by 18 days when cultures were discontinued.

\section{Evaluation of colds}

The symptom diary was based on that used by Jackson et al. [16] recording upper respiratory tract symptoms (rhinorrhoea, nasal blockage and sneezing) and systemic symptoms (headache, malaise and chills). Each symptom was scored from $0-3$ points according to severity. The criteria of JACKSON et al. [16] were then modified by a previously validated method [17] in order to categorize volunteers by upper respiratory tract score into the following groups: definite cold (a score of $\geqslant 2$ above a zero baseline on at least two consecutive days over days 2-6 post-inoculation); possible cold (a marginal increase over a zero baseline or a score of $\geqslant 2$ above a symptomatic baseline on at least two consecutive days over days 2-6); and no cold (symptom-free).

Laboratory confirmation of infection was by reverse transcriptase polymerase chain reaction (RTPCR) of virus ribonucleic acid (RNA) extracted from nasal lavages obtained on day 3 postinoculation. This followed a previously established method [13].

\section{Evaluation of ciliary structure and function}

Prior to viral inoculation and 3 days after inoculation, ciliated samples were obtained by brushing the inferior nasal turbinate with a 2-mm cytology brush (BC-15C Keymed, Southend-on-Sea, UK) [18]. This has been found to be an ideal site for repeated sampling of ciliated epithelium [3]. Day 3 was chosen, as previous studies of viral infections found little effect during the first 2 days and very significant changes to the respiratory epithelium on day 4 [2]. Nasal brushings were placed in Medium 199 (25 mM hydroxyethyl piperazine ethane sulphonic acid, Earles salt, L-glutamine ( $\mathrm{pH}$ 7.3)) which contained antibiotic solution (streptomycin $50 \mu \mathrm{g} \cdot \mathrm{mL}^{-1}$, penicillin $50 \mu \mathrm{g} \cdot \mathrm{mL}^{-1}$, GibcoBR Life Technologies, Paisley, UK).

Transmission electron microscopy. Tissue obtained by nasal brushing was fixed in $2.5 \%$ gluteraldehyde in Sorensons phosphate buffer for $48 \mathrm{~h}$ and then post fixed in $1 \%$ osmium tetroxide. After rinsing in distilled water, the cells were embedded in a drop of $2 \%$ liquid agar at $45^{\circ} \mathrm{C}$ and allowed to solidify. This was processed through to resin by standard techniques. Ultrathin sections were cut at $70 \mathrm{~nm}$. These were collected on 200 mesh thin-bar copper grids and stained in $1 \%$ uranyl acetate and counter stained in Reynolds lead phosphate. The sections were then examined by transmission electron microscopy.

The ciliated epithelium was assessed, in a blind fashion, for both epithelial and ciliary ultrastructural changes. Epithelial integrity was assessed firstly by assessing cell type. The number of ciliated cells, mucous cells, and dead cells were expressed as a percentage of all cells examined. Secondly, disruption and damage to the tissue was quantified using the scoring system described by Tsang et al. [19]. Briefly, the tissue was scored for the following parameters: loss of cilia from ciliated cells: 0 (fully ciliated), 1, 2, 3 ( $3=$ few cilia visible); projection of cells from the epithelial edge: 0 (normal alignment), 1, 2, 3 ( $3=$ cell projected from edge but some contact with other epithelial cells); cytoplasmic blebbing: 0 (absent), 1 (minor), 2 (major); mitochondrial damage: 0 (absent), 1 (present) [19].

Damage to individual cilia was evaluated by examining ciliary ultrastructure for microtubular and dynein arm defects. Alignment of individual cilia within a cell was determined by measuring ciliary orientation [20].

Percentages were calculated for the number of cells with loss of cilia, cellular projections, cytoplasmic blebbing and mitochondrial damage. Similarly, the percentage of cells with microtubular or dynein arm defects was calculated.

Ciliary beat frequency and beat pattern. Ciliated strips of epithelium were suspended in a chamber created by the separation of a cover slip and glass slide by two adjacent cover slips. The slide was placed on a heated stage $\left(37^{\circ} \mathrm{C}\right)$ of a Leitz, Diaplan microscope mounted on an antivibration table (Wentworth Laboratories Ltd, Sandy, Bedfordshire, UK). Specimens were examined using a $\times 100$ interference contrast lens. Only undisrupted ciliated strips of $>50 \mu \mathrm{m}$ in length were studied.

Beating ciliated edges were recorded using a digital 
Table 1. - Epithelial cell types pre- and postvirus or sham inoculation

\begin{tabular}{lllr}
\hline & Ciliated cells & Dead cells & Mucous cells \\
\hline Corona & & & \\
$\quad$ Day 0 & $63.7(46.8-80.6)$ & $0.0(0.0-0.0)$ & $10.2(3.1-17.3)$ \\
$\quad$ Day 3 & $20.5(3.8-37.2)^{*}$ & $6.3(1.4-11.2)^{*}$ & $11.5(7.5-15.5)$ \\
Sham & $72.0(66.2-77.8)$ & $0.0(0.0-0.0)$ & $9.2(7.8-10.6)$ \\
$\quad$ Day 0 & $70.1(67.5-72.7)$ & $0.0(0.0-0.0)$ & $99(8.3-11.5)$ \\
$\quad$ Day 3 & $-41.3(-80.7--1.8)^{*}$ & $6.3(0.5-12.2)^{*}$ & $0.58(-12.2-13.3)$ \\
$\quad$ Coup difference & &
\end{tabular}

Data are presented as mean percentage (95\% confidence interval). ${ }^{*}$ : difference between changes from baseline in the two groups, i.e. (day 3-day 0)corona-(day 3-day 0)sham. *: p<0.05.

high-speed video camera (Kodak Motioncorder 1,000 , Kodak, San Diego, CA, USA) at a rate of 400 frames $\cdot \mathrm{s}^{-1}$, using a shutter speed of 1 in 4,000 as previously described [21]. Briefly, the camera allowed video sequences to be replayed at reduced frame rates or frame by frame. This allows the precise movement of individual cilia to be observed during their beat cycle. Ten readings of ciliary beat frequency (CBF) were taken from different areas along each ciliated edge.

To assess the ciliary beat pattern each edge was given a score based on the following scoring system. Normal coordinated ciliary beating in a forward backward motion was scored as 0 . Cilia that appeared to beat dyskinetically were scored from 1-3 depending on the extent of abnormal beating along the edge (all cilia along an edge beating dyskinetically scored 3 ).

$\mathrm{CBF}$ was determined directly. Groups of beating cilia were identified and the number of frames required to complete 10 cycles was recorded. This was converted to $\mathrm{CBF}$ by a simple calculation $(\mathrm{CBF}=400 /$ (number frames for 10 beats $) \times 10$ ) [21].

\section{Statistical analysis}

The mean and 95\% confidence interval (CI) for each group was calculated for day 0 and day 3 for all parameters measured. The mean change from baseline (day 3-day 0) and 95\% CIs were calculated. Results which did not encompass 0 suggested a difference between day 0 and day 3, which was analysed by a paired-samples t-test. A Wilcoxon signed-rank test was used to compare the dyskinetic beat pattern on day 0 and day 3.

An unpaired t-test was used to group differences expressed as the change from baseline for both groups i.e.: (day 3-day 0)corona against (day 3-day 0)sham. This was expressed as mean difference between groups and $95 \%$ CI.

\section{Results}

Three of 11 volunteers inoculated with $\mathrm{HCoV}$ had no symptoms of a cold. Four developed a definite cold and four had a "possible cold". Of the volunteers who developed a definite or possible cold, all suffered mild upper respiratory tract symptoms. Six of these subjects developed a headache, four a cough and two a fever. Three of the four with definite colds and one of the four with possible colds had virus RNA detected in nasal secretions. Viral RNA was not detected in the four volunteers without symptoms of a cold. Two of the subjects inoculated with UV-inactivated virus developed a mildly blocked nose lasting for $<24 \mathrm{~h}$, commencing 2 days after inoculation. No other symptoms were reported in this group.

All subjects inoculated with active $\mathrm{HCoV}$, including the three who did not develop symptoms of an upper respiratory tract infection, had disruption of their respiratory epithelium on day 3 . Eight paired samples, before and after inoculation with active virus, were obtained from the 11 volunteers for transmission electron microscopy and comparison of ciliary function.

Table 1 summarizes the changes seen in cellular type. After inoculation with $\mathrm{HCoV}$, there was a significant reduction in the proportion of ciliated cells $(\mathrm{p}<0.05)$ and an increase in the proportion of dead cells $(\mathrm{p}<0.05)$. No changes were seen in the percentage of mucous cells.

Epithelial disruption and damage by quantification of cilia loss, cellular projections, cytoplasmic blebbing and mitochondrial damage were all significantly increased on day $3(\mathrm{p}<0.05)$ (table 2, figs. 1a and $1 \mathrm{~b})$.

Assessing ciliary ultrastructure (table 3 ), a small increase in microtubular abnormalities $(\mathrm{p}<0.05)$ was found on day 3 . No differences were found between day 0 and day 3 for both dynein arm defects and ciliary orientation. No significant change was seen between the mean CBF on day 0 and day 3 (table 3 ), but cilia were found to beat dyskinetically on day 3 $(\mathrm{p}<0.05)$.

No change in structure or function was found in samples from volunteers inoculated with UVinactivated virus (tables 1-3). Comparison of the change from baseline between subjects inoculated with either active $\mathrm{HCoV}$ or $\mathrm{UV}$-inactivated virus showed significant differences between groups in: loss of ciliated cells, increase in dead cells, cells with loss of cilia, cellular projections, cytoplasmic blebbing, mitochondrial damage, microtubule defects and ciliary dyskinesia (tables 1-3).

\section{Discussion}

The present results demonstrate that significant damage to the respiratory epithelium occurs following 
Table 2.-Assessment of epithelial integrity pre- and postvirus or sham inoculation

\begin{tabular}{lllcc}
\hline & \multicolumn{1}{c}{$\begin{array}{c}\text { Cells with loss } \\
\text { of cilia }\end{array}$} & $\begin{array}{c}\text { Cells extruding } \\
\text { from surface }\end{array}$ & $\begin{array}{c}\text { Cells with cytoplasmic } \\
\text { blebbing }\end{array}$ & $\begin{array}{c}\text { Cells with mitochondrial } \\
\text { damage }\end{array}$ \\
\hline $\begin{array}{l}\text { Corona } \\
\text { Day 0 }\end{array}$ & $28.1(15.4-40.8)$ & $25.8(21.5-30.1)$ & $15.1(10.7-19.5)$ & $11.9(5.4-18.4)$ \\
$\quad \begin{array}{l}\text { Day 3 } \\
\text { Sham }\end{array}$ & $97.9(93.8-101.9)^{*}$ & $63.4(51.5-75.3)^{*}$ & $36.3(24.2-48.4)^{*}$ & $44.2(33.8-54.6)^{*}$ \\
$\quad$ Day 0 & $31.9(26.4-37.4)$ & $25.7(22.1-29.3)$ & $17.6(10.2-25.0)$ & $10.4(5.8-15.0)$ \\
$\quad \begin{array}{l}\text { Day 3 } \\
\text { Goup difference } \\
\text { Corona - sham }\end{array}$ & $23.3(18.6-28.0)$ & $21.4(20.9-21.9)$ & $17.1(12.7-21.5)$ & $12.6(3.7-21.5)$ \\
\hline
\end{tabular}

Data are presented as mean percentage $\left(95 \%\right.$ confidence interval). ${ }^{*}:$ difference between changes from baseline in the two groups, i.e. (day 3-day 0)corona-(day 3-day 0)sham. *: $\mathrm{p}<0.05$; ***: $\mathrm{p}<0.001$.

nasal inoculation with $\mathrm{HCoV}$, even in those without overt clinical symptoms of a cold. Evidence of disruption of the nasal epithelium and ciliary dyskinesia was found in all of the volunteers inoculated with active $\mathrm{HCoV}$ even though three subjects had no symptoms of a cold. No epithelial damage was seen in subjects who were sham infected with inactivated virus. The lack of damage following sham infection suggests that tissue damage is a result of an infective process, rather than an immune-mediated response to viral antigen, or the effect of cytokines present in the inoculum, since it only occurs when live virus is administered.
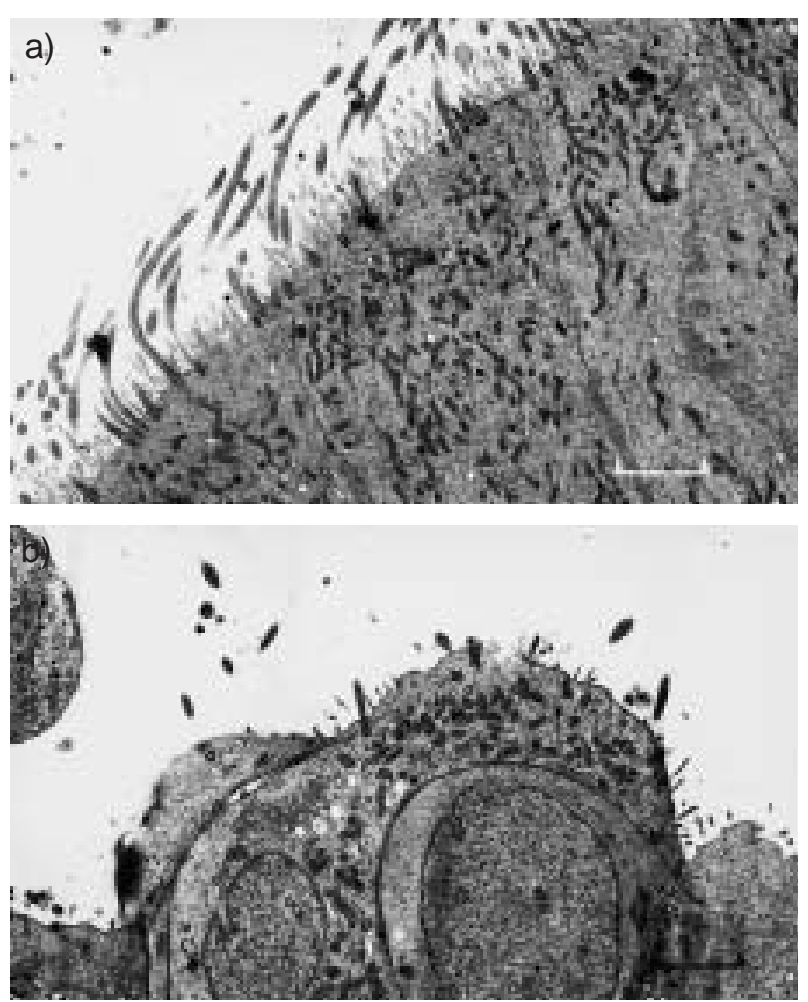

Fig. 1.- Transmission electron micrograph of nasal epithelium before and after coronavirus inoculation. a) Transmission electron micrograph day 0 . This shows normal tissue with an intact wellciliated surface and minimal disruption. b) Transmission electron micrograph day 3. This shows abnormal tissue with severely disrupted cell surface. Marked loss of cilia is seen. Internal scale bars $=2.9 \mu \mathrm{m}$.
Although analysis of epithelium was blinded, inoculation was not blinded or placebo controlled. Nevertheless, the nasal measurements suggest that the model was successful, with clear evidence of epithelial damage in all of those inoculated and with clinical symptoms of a cold in the majority. RT-PCR was chosen as the method to identify $\mathrm{HCoV}$, as it has been shown to be more sensitive than either serology or culture techniques [13]. In retrospect, serology and cell culture might have provided useful additional laboratory evidence of infection. The RT-PCR results were only positive in a proportion of those inoculated despite epithelial damage in all cases. The reasons for this may be related to the timing of samples, sample quality and the possibility of false-negative results arising during the RT-PCR assay.

Despite the fact that only four volunteers were sham infected, clear differences between volunteers inoculated with active $\mathrm{HCoV}$ and sham-infected subjects were found. Within the sham-infected group, there was no evidence of epithelial damage or ciliary dyskinesia 3 days after inoculation. This suggests that viral antigens or mediators within the inoculum were not responsible for the epithelial changes found. It appears that infection with active virus is required for epithelial damage to occur.

BENDE et al. [7] made physiological measurements on 24 adult volunteers inoculated with $\mathrm{HCoV}$, of whom 13 developed clinical symptoms, eight had no overt clinical symptoms but viral shedding occurred, and three were not infected. Nasal airway resistance and the temperature of the nasal mucosa increased in those with and without symptoms, suggesting underlying inflammation in both groups. Mucosal blood flow in the nose and nasal mucous secretion increased only in those with symptoms. These results are consistent with the present findings that an inflammatory process may be occurring in volunteers inoculated with $\mathrm{HCoV}$ who show no clinical signs of a cold.

Overt viral upper respiratory tract infections usually delay nasal mucociliary clearance [5]. Loss of ciliated epithelium and dyskinetically beating cilia may be a major factor in this, although a change in mucus rheology may also be important [6]. In this study, the duration of symptoms peaked at day 4 and resolved 7 days after inoculation. The present study only provides data 3 days after inoculation. The time taken for the upper respiratory tract epithelium to 
Table 3. - Ciliary function and ultrastructural analysis pre- and postvirus or sham inoculation

\begin{tabular}{lcccccc}
\hline & CBF Hz & $\begin{array}{c}\text { Ciliary } \\
\text { dyskinesia score }\end{array}$ & $\begin{array}{c}\text { Dynein arm } \\
\text { defects \% }\end{array}$ & $\begin{array}{c}\text { Microtubule } \\
\text { defects \% }\end{array}$ & $\begin{array}{c}\text { Central } \\
\text { microtubule defects \% }\end{array}$ & $\begin{array}{c}\text { Ciliary } \\
\text { orientation }\end{array}$ \\
\hline $\begin{array}{l}\text { Corona } \\
\text { Day 0 }\end{array}$ & $11.3(8.6-14.0)$ & $0.2(0-0.5)$ & $1.3(0.3-2.3)$ & $2.6(1.4-3.8)$ & $0.3(0.0-0.6)$ & $10.6(10.1-11.1)$ \\
$\quad$ Day 3 & $9.4(7.2-11.6)$ & $1.1(0.5-1.7)^{*}$ & $2.9(0.8-5.0)$ & $4.7(3.2-62)^{*}$ & $1.0(0.1-1.9)$ & $11.4(10.4-12.4)$ \\
$\begin{array}{c}\text { Sham } \\
\quad \text { Day 0 }\end{array}$ & $11.9(11.6-12.2)$ & $0.1(0.0-0.0)$ & $0.9(0.0-22)$ & $2.2(1.0-3.4)$ & $0.0(0.0-0.0)$ & $10.7(10.0-11.4)$ \\
$\quad \begin{array}{l}\text { Day 3 } \\
\text { Group difference } \\
\quad \text { Corona-sham }\end{array}$ & $10.8(10.1-11.5)$ & $0.2(0.0-0.4)$ & $1.2(0.1-2.3)$ & $2.3(0.8-3.8)$ & $0.0(0.0-0.0)$ & $11.0(10.3-11.7)$ \\
\hline
\end{tabular}

Data are presented as mean $\left(95 \%\right.$ confidence interval). CBF: ciliary beat frequency. ${ }^{*}$ : difference between changes from baseline in the two groups, i.e. (day 3-day 0)corona-(day 3-day 0)sham. ${ }^{*}: \mathrm{p}<0.05$.

return to normal following exposure to coronavirus infection is not known. In naturally-acquired colds, the epithelium returns to normal in the majority of patients by 3 weeks [1], while mucus clearance may be abnormal for several weeks following viral infection [5].

A major advantage of using a digital high-speed video system for ciliary analysis is the ability to play ciliary movement in slow motion, allowing both measurement of their beat frequency and evaluation of their beat pattern. Despite recording beat frequency within the normal range 3 days after inoculation with $\mathrm{HCOV}$ a significant increase in dyskinetic cilia was seen. The readings of $\mathrm{CBF}$ are made at physiological temperatures with cilia beating at $>11 \mathrm{~Hz}$. Such high frequencies mean that it is usually impossible to assess dyskinetic movement without the ability to watch them in slow motion. Pedersen et al. [5] studied ciliary function at $22^{\circ} \mathrm{C}$, following naturally-acquired common colds. At this temperature, cilia beat at half of their normal rate, allowing gross changes in beat pattern to be more easily detected. They also noted a significant increase in ciliary asynchrony that was maximal during the first few days of the infection. Others have also found $\mathrm{CBF}$, measured at physiological temperatures, to be within the normal range following viral infection, but they have not commented on the presence of dyskinesia It is possible that ciliary dyskinesia was missed due to the rapid beat frequency [2].

Electron microscopy showed significant loss of epithelial integrity and a very significant decrease in the number of ciliated cells after coronavirus inoculation. Similar findings have been recorded following nasal infection with other viruses [5, 6, 22, 23].

On day 3 , the authors found a small increase in peripheral and central microtubular abnormalities. This is less than previously reported in naturallyacquired viral infection in children [3], although none of the patients in that study had a coronavirus infection. In 22 of the 30 episodes of culture-proven viral infection, CARSON et al. [3] found microtubular additions and deletions. In the remaining eight cases, epithelial cell abnormality and the loss of ciliated cells were too severe to allow ciliary structure to be evaluated. Beat frequency or analysis of ciliary dyskinesia was not explored [3].
No virions were seen on electron microscopy in the present study despite epithelial damage. This is in keeping with other reports of electron microscopy of human nasal and bronchial epithelium during episodes of the common cold [1, 3, 24, 25]. In contrast, there are many published reports of in vitro coronavirus-infected cells [26-28]. AfZELIUs [11] documented a single case of coronavirus infection of the nasal respiratory epithelium in a 2-yr-old girl with no symptoms of a common cold. This was an incidental finding on a biopsy taken to rule out the diagnosis of primary ciliary dyskinesia. Virions could be seen within and outside the ciliated cells but not in the mucous cells. Some virions were located near the microvilli with others in pockets in the apical cell membrane, suggesting the microvilli may be the site of first contact.

Damage to the respiratory epithelium may occur due to viral infection without overt clinical symptoms. This may well have implications in lung disease; for example in chronic suppurative diseases, where lung function was significantly reduced following symptomatic and asymptomatic viral infections [29]. Further work is needed to establish the mechanism of viral damage to the respiratory epithelium caused by human coronavirus infection.

Acknowledgements. The authors would like to thank J. Thompson, senior lecturer in statistics at the University of Leicester, for statistical advice. The authors also thank the virology laboratory at the Leicester Royal Infirmary for their support.

\section{References}

1. Rautiainen M, Nuutinen J, Kiukaanniemi H, Collan Y. Ultrastructural changes in human nasal cilia caused by the common cold and recovery of ciliated epithelium. Ann Otol Rhinol Laryngol 1992; 101: 982-987.

2. Wilson R, Alton E, Rutman A, et al. Upper respiratory tract viral infection and mucociliary clearance. Eur J Respir Dis 1987; 70: 272-279.

3. Carson JL, Collier AM, Hu SS. Acquired ciliary defects in nasal epithelium of children with acute viral upper respiratory infections. $N$ Engl J Med 1985; 312: 463-468. 
4. Sakakura Y. Changes of mucociliary function during colds. Eur J Respir Dis Suppl 1983; 128: 348-354.

5. Pedersen M, Sakakura $Y$, Winther B, Brofeldt S, Mygind N. Nasal mucociliary transport, number of ciliated cells, and beating pattern in naturally acquired common colds. Eur J Respir Dis Suppl 1983; 128: 355-364.

6. Sakakura Y, Sasaki Y, Hornick RB, et al. Mucociliary function during experimentally induced rhinovirus infection in man. Ann Otolaryngol 1973; 82: 203-211.

7. Bende M, Barrow I, Heptonstall $\mathrm{J}$, et al. Changes in human nasal mucosa during experimental coronavirus common colds. Acta Otolaryngol 1989; 107: 262-269.

8. Monto AS. Coronaviruses. In: Evans AS, ed. Viral Infections of Humans. New York, Plenium Book Company, 1982; 151-165.

9. Johnston SL, Pattemore PK, Sanderson G, et al. Community study of role of viral infections in exacerbations of asthma in 9-11 year old children. BMJ 1995; 310: 1225-1229.

10. Tyrrell DAJ, Bynoe ML. Cultivation of a novel type of common-cold virus in organ cultures. $B M J 1965 ; 1$ : $1467-1470$.

11. Afzelius BA. Ultrastructure of human nasal epithelium during an episode of coronavirus infection. Virchows Archive 1994; 424: 295-300.

12. Macnaughton MR, Madge MH, Reed SE. Two antigenic groups of human coronaviruses detected by using enzyme-linked immunosorbent assay. Infect Immun 1981; 33: 734-737.

13. Myint S, Siddell S, Tyrrell D. Detection of human coronavirus $229 \mathrm{E}$ in nasal washings using RNA: RNA hybridization. J Med Virol 1989; 29: 70-73.

14. Gwaltney JM Jr, Hendley O, Hayden FG, et al. Updated recommendations for safety-testing of viral inocula used in volunteer experiments on rhinovirus colds. Prog Med Virol 1992; 39: 256-263.

15. Johnston SL, Papi A, Bates PJ, Mastronarde JG, Monick MM, Hunninghake GW. Low grade rhinovirus infection induces a prolonged release of IL- 8 in pulmonary epithelium. J Immunol 1998; 160: 6172 6181.

16. Jackson GG, Dowling HF, Speisman IG, Boand AV. Transmission of the common cold under controlled conditions. 1. The common cold as a clinical entity. Arch Intern Med 1958; 101: 267-278.

17. Mckean MC, Leech M, Lambert PL, Hewitt C, Myint
S, Silverman M. A model of viral wheeze in nonasthmatic adults: symptoms and physiology. Eur Respir J 2001; 18: 23-32.

18. Rutland J, Cole PJ. Non-invasive sampling of nasal cilia for measurement of beat frequency and study of ultrastructure. Lancet 1980; 2: 564-565.

19. Tsang KWT, Rutman A, Tanaka E, et al. Interaction of Pseudomonas aeruginosa with human respiratory mucosa in vitro. Eur Respir J 1994; 7: 1746-1753.

20. Rayner FJ, Rutman A, Dewar A, Greenstone MA, Cole PJ, Wilson R. Ciliary disorientation alone as a cause of primary ciliary dyskinesia. Am J Respir Crit Care Med 1996; 153: 1123-1129.

21. Chilvers MA, O'Callaghan C. Analysis of ciliary beat pattern and beat frequency using digital high speed imaging: comparison with the photomultiplier and photodiode methods. Thorax 2000; 55: 314-317.

22. Hoorn B, Tyrrell DA. Effects of some viruses on ciliated cells. Am Rev Respir Dis 1966; 93: Suppl. 156161.

23. Tristram DA, Hicks W Jr, Hard R. Respiratory syncytial virus and human bronchial epithelium. Arch Otolaryngol Head Neck Surg 1998; 124: 777-783.

24. Giorgi PL, Oggiano N, Braga PC, et al. Cilia in children with recurrent upper respiratory tract infections: ultrastructural observations. Pediat Pulmonol 1992; 14: 201-205.

25. Winther B, Brofeldt S, Christensen B, Mygind N. Light and scanning electron microscopy of nasal biopsy material from patients with naturally acquired common colds. Acta Otolaryngol 1984; 97: 309318.

26. Becker WB, McIntosh K, Dees JH, Chanock RM. Morphogenesis of avian infectious bronchitis virus and a related human virus (strain 229E). J Virol 1967; 1: 1019-1027.

27. McIntosh K, Dees JH, Becker WB, Kapikian AZ, Chanock RM. Recovery in tracheal organ cultures of novel viruses from patients with respiratory disease. Proc Natl Acad Sci USA 1967; 57: 933-940.

28. Evermann JF, Heeney JL, McKeirnan AJ, O'Brien SJ. Comparative features of a coronavirus isolated from a cheetah with feline infectious peritonitis. Virus Res 1989; 13: 15-27.

29. Collinson J, Nicholson KG, Cancio E, et al. Effects of upper respiratory tract infections in patients with cystic fibrosis. Thorax 1996; 51: 1115-1122. 